\title{
Social Media and Productivity: The Case of Education Sector in Assir Province
}

\author{
Hamed J. H. Usrof \\ City University College of Ajman \\ Khalifa Bin Zayed Road, College Street, Al Nuimia, Ajman, United Arab Emirates \\ E-mail: dr.hamedusrof@gmail.com
}

Received: July 12, 2017 Accepted: July 25, 2017 Online published: August 7, 2017

doi:10.5296/ijhrs.v7i3.11660 URL: https://doi.org/10.5296/ijhrs.v7i3.11660

\begin{abstract}
Employees deemed as one of the most critical elements of several institutional models. The named educational institutions in this research are notable in Assir Province, Saudi Arabia and have a sizeable figure of professional human resources. The unprecedented progress of different organization depends on employees' productivity and performance. Social media platforms (SMPs) that are robustly dominant have permeated the workplace, and most institutional employees are exercising the ubiquity of the platforms without unspecified access restriction. The objective of this investigation is to measure the degree of SMPs usage by institutional employees and its repercussions on their productivity. Also, review the relevant acumens of the platforms. The research focused on the employees with a total of 300 questionnaires has distributed that consist of 29 survey items, divided into three sections. The proceeds from our research inferred that SMPs had utilized in the workplace for both business and non-business paralleled activity. SMPs can be a valuable instrument to strengthen employee productivity through collaborations of knowledge formulation and sharing. Nevertheless, it can also become an immense perplexity and efficiency-eater in the work performance as well as impede the resources of the institution if not handled perfectly.
\end{abstract}

Keywords: Education, Employee Productivity, Social Media Platforms, Saudi Arabia

\section{Introduction}

Saudi Arabia as a noticeable Middle Eastern society both culturally and economically has contributed an innovative and distinctly impressive illustration when witnessed within the 
transparent glass of online social media. The top influential social media platforms (SMPs) like Facebook, Twitter, Instagram, Google+, and LinkedIn have established with millions of users athwart the country and boosted its economic share in the recent year, both in quantities and percentage of users are publicized in Table 1. With 20.29 million (63.7 percent) recorded users, 34.53 percent active social media accounts, and 31.4 percent social accounts Facebook through mobile phone infiltrate the social media charts (Global Media Insight, 2016). The reputation of the current state of online technology (Web 2.0) and social media applications apparently designate and authorize individual users and organizational users to communicate dynamically. Also, share as well as produce content relating to these platforms. For this understanding, SMPs described as web-based platforms that enable employees to firstly, write messages to particular co-employees or transmitted messages to everybody in the educational institutions; secondly, explicitly show or ultimately exhibit to subordinates as communication associates. Thirdly, they sort text, post, and edit files connected to them; and lastly, view the messages, selected, sorted, communicated, and posted by other employees at their available time (Leonardi et al., 2013).

In recent years, SMPs becomes imperative for community operating in higher education to traverse the attractive significances of new technologies deliver to institutions, educators, and scholars. In training and learning community, the participation of faculty and the non-faculty staff is approximately horrendous to be without universal internet access to the SMPs. Considering its inception over a decade, the ubiquity of SMPs has become both indispensable instruments for and a reflector of individual uniqueness, and also network building among employees and learners. For others, these platforms are not appealing, or they might be excited in using them for a purpose, such as for seeking erudition and establishing a potential business opportunity, etc. But for faculties, employing SMPs as well as what principles they see with the approach of digital information and communication are a frame of the instructional method. Comparable to other organizations, educational institutions implement and benefit from multiple communication and collaboration of technologies. Experimental analyses explained that interactive character of online and mobile technologies could formulate a desirable learning and training framework (Seaman and Tinti-Kane, 2013).

The past studies have generated a dynamic augmentation and acumens into the propensity of SMPs. Nevertheless, their enactment in the workplace is moderately remained dubious. In the context of management, SMPs have obtained the authenticity of lessening productivity and rising interpersonal confusion. Moreover, unmediated appearance to different content can have a corrupting impression on morality and spirituality of individuals in the kingdom (Sait et al., 2007). While the previous investigation has predominantly concentrated on the immediacy of the mechanism, the integrated impact of SMPs in the educational arena has disregarded. If institutions want to manage with these platforms, then they require procedures to elevate the knowledge of efficient SMPs usage for depreciating plausible hindrances. In general, this research is to measure the degree of SMPs usage by employees and its repercussions on their productivity and review the critical understanding of these platforms. 
Table 1. Top active social network platforms in Saudi Arabia as per 2016

\begin{tabular}{lccc}
\hline Social Media Platforms & Year Created & No. of users & Percentage (\%) \\
\hline Facebook & 2004 & 7.96 million & 25 \\
Twitter & 2006 & 6.37 million & 20 \\
Instagram & 2010 & 5.41 million & 17 \\
Google+ & 2011 & 4.77 million & 15 \\
LinkedIn & 2002 & 3.50 million & 11 \\
\hline
\end{tabular}

Source: Global Media Insight, 2016

\section{Employee Productivity and Social Media Platforms}

Linna et al. (2010) described productivity as a ratio of the quantity of product produced per unit of input. Figuratively, if we provide a high degree of the contribution from the related sources, it will enhance productivity. Or if we implement the equal quality of the limited resources, can further improve productivity. In this section, productivity attributes to the evaluation of the effectiveness of employees at an appropriate time. Or period conferred by an employee actively completing the assignment to deliver high quality of the coveted results which changed to be the hallmarks of institutional growth. The ubiquitous usage of SMPs in education possesses a remarkable influence on employees' behavior, positively and negatively. Adopting social media has the individuals' direction of thinking/reason and communicating, as well as accumulating and distributing knowledge and learning (Bonds-Raacke and Raacke, 2010) which directed to grasping numerous innovative teaching methods as well as students' education practices.

In a reasonable evaluation, SMPs seemed related to a tremendous misuse of time at work and a significant damage to educational institutions. Although, different investigations have ascertained that SMPs may progress employees' productivity through assertiveness. For instance, utilizing SMPs in a regular college program can be transformed the classroom response of both lecturer and scholars that were occurring in an efficient synergy, solving problems and possibilities to strengthen their distinctive concentrations and personal abilities (Griesemer, 2014). Additionally, SMPs assists instructors to communicate and involve modest learners who are further prompt to participate in the class conversation if they are unidentified or at least not in person within the classroom. These are the motives why a few instructors have encompassed social media as a significant pedagogical medium for teaching and learning (Papandrea, 2012).

Social media can support its employees to be productive and promotes educational institutions with the incredible knowledge and information which is required to remain on top of the education industry. For instance, PBS Learning Media in U.S. carried a national survey for pre-K to 12th-grade teachers. The research spanned 503 web-based interviews with a margin of error $+/-4.4$ percent at a 95 percent confidence level. It determined that 74 percent of teachers applied digital support to augment and strengthen on content within their classrooms and 74 percent of teachers encourage the student to learn. Further, 73 percent of students respond to a mixture of learning provided by faculty, and 69 percent of students do 
several additional exercises than ever before, with the necessary used of resources, for instance, being online lesson plans, interactive web games and online articles (Larson, 2013). According to the raised significant influence of determinants, the research inferred that institutions should apply agreeable use management strategies coupled with other security of technologies to control the proper access of SMPs.

\section{Social Media Platforms in the Kingdom}

In the Kingdom, the advent of information and communication in the framework of social media is a particular element of ordinary life as important an essential as water, food, and shelter since it is improbable to visualize living without it. For Arab individual, it depreciates the predicament of information and interaction to other community or individual in miles away and hustles the capability of individual to share or exchange information at their convenience (Hantula et al., 2011). Several of the leading platforms in social media posted on top provide the society a piece of knowledge to comfortably unite with relatives, friends, and associates. Instagram, as a SMP published in October 2010 and reported as entertainment and unorthodox style of communication to captivate and share the world's significances from a mobile phone. Differentiate to other SMPs, Instagram has its filter to produce an image with the great appearances. Filters can further convert an ordinary image into an object that worth sharing without considerable work. Google Plus initially described the environment as a social network, and suddenly defines as a social layer which improves the current contexts and platforms of Google (Bosker, 2012). In the kingdom, Google Plus has touched the social network community with 4.77 million Saudi supporters.

Next, Twitter is a micro-blogging platform which has started in July 2006. It is a grotesque structure of communication due to the fact of its compactness on the message postings: the limit is 140 characters, and the online subscribers have no obligation to be associated with each other. Over 2016, Twitter had 6.37 million online Saudi customers. A critical acumen concerning the Twitter is that Saudi users tweeted five times per day, and 87 percent of these posts are re-tweets. On the contrary, LinkedIn is further business platform oriented and has 3.50 million online members. The internet members pin up their professional image and content to the society, reaching other practitioners in their discipline, displaying their abilities, and indeed seeking for considered competitors for their applications (Cox and Rethman, 2011). Pursuing this further, Facebook, which is the leading social in online landscape, declared they had over 7.96 million active Saudi subscribers in 2016, with most of these online users comprising young men aged between 25 and 34. The explicit recognition of a new breed of mobile phones and the progressions of innovation in mobile internet technology are the primary external forces behind the upsurge of social media in the nation. According to Baghdadi's report (2015), the average active Facebook member posts approximately ten times per week.

As with organizations in general, employees at three representative institutions (King Khalid University, Prince Sultan College, and Al-Ghad College) have sophisticated computers and internet knowledgeability and experience levels. The sample organizations, as a tertiary education institution, have the chance to perform internet and online SMPs to stimulate its 
employees' productivity positively and to strengthen collaboration among its employees. Still, workers consume extra period on social media involving in non-work specific exercises or so-called "cyberloafing" such as formulating personal networks, streaming and downloading music and video, reviewing sports scores, following social bookmarks, and monitoring on family and friends. This investigation intended to ascertain whether employees of educational institutions had previously used, were using or would be involved in using SMPs in a professional atmosphere and what influences the unlimited use of SMPs technology perhaps had on the productivity of these employees.

The advancement of social media plan and internet usage policies in by educators are at the initial stage. Several institutional managers do not have standard policies, despite the fact that the system has commanded the use of absolute authority and limitation. One of the difficulties of these educational institutions is to advance employee productivity to boost earnings and take measure in wastage of resources. These institutions would be the focal point of extensive education, carrying into the attention of the dynamic world situation, provided towards poverty mitigation, welfare modernization, and improvement of science and technology. To achieve these requirements, Saudi Arabia required information and communication technology as imperative and compelling.

This research, consequently, attempts to examine the impacts of SMPs in the workplace on employee productivity. To discuss the analysis challenge affirmed, the researchers have considered the following sub-questions.

- What are the common social media platforms?

- Do social media ties societies online in a consistent, serviceable practice?

- What are the probable outcomes if employees are authorized to approach SMPs without limitation?

- How can SMPs support to the productivity of an organization, specifically the three institutions?

- What are the available benefits and drawbacks that SMPs could have for the educational institutions?

\section{Research Materials and Methods}

The objective of this examination was to ascertain the impact of SMPs on employee productivity within the three sample institutions of Assir Province, Saudi Arabia. The investigation attended was analytical study, and the data has settled with the help of a surveyed items and interview in a cross-sectional outline.

\subsection{Population}

The target population of the research contained the volume of employees that stayed or visited in the SMPs for the period under examination. The populace for the study was the SMPs usage of preferred employees in various institutions of Assir Province, Saudi Arabia. The three organizations are King Khalid University, Prince Sultan College, and Al-Ghad 


\section{Ml Macrothink \\ International Journal of Human Resource Studies \\ ISSN 2162-3058 \\ 2017, Vol. 7, No. 3}

College. All the target groups have internet access in their workplace.

Considering there are several sections of respondents, the researcher's crew manages to use stratified sampling approach. For the notion of obtaining data on employees' internet access, the researchers sorted out the potential respondents that can request in this research as "temporary staff" and "permanent staff" doing their responsibilities as a full-time employee. This arrangement is given taking into account the extent of the Internet technological knowledge of employees and the variety of information demanded from them.

\subsection{Participants}

The participants for this analysis were from a social community who has internet connectivity in their workplace. An entirety of 300 questionnaires has distributed that consist of 29 survey items, sorted into three classes. Initially, 180 survey items have responded; nevertheless, 150 were applicable since 30 questionnaires remained unfinished or mistakenly filled out. The participants were determined using randomly sampling procedure in which the researchers chooses these employee participants from diverse institutions as this section is reflected to mirror the entire employees in each educational body with relating to the characteristic in question.

\subsection{Data Collection Techniques}

Data have collected over a period of four months; between Augusts to December 2015 from various institutions in Assir Province, Saudi Arabia. For the scope of data collection, the researchers applied survey items, interviews and discussions, and observations. Respondents who used SMPs were invited to complete the sampling. Nearly all questions were being close-ended to improve the validity of the response. Subsequent information has collected by suggesting to corporate articles, classified excellent writings, and demographic figures of official production, contextual analyses, and factual websites such as Science Direct, EBSCOhost, ProQuest, and Emerald Insight.

\subsection{Procedures}

For the scope of data samples, the researchers applied three data collection instruments which are interviews and discussions, survey items, and observations. First, all potential respondents were scaled based on their availability. Next, simple random sampling methods were utilized to choose respondents from each level. Lastly, the selected respondents were questioned and provided questionnaires.

\subsection{Data Analysis and Discussion}

After compilation of the data has gathered, the researchers applied descriptive data analysis method for the particular intentions which have considered. A sequence of observations and criticisms of the solicited data carried out thoroughly to conclude which SMPs are continuously accessed, non-work related. The reasonable time an employee wasted to access these online platforms per day or week and to examine impacts of SMPs on workforces' productivities. Lastly, by merging all the examinations and interpretations, the researchers was concluding the extent that employees waste working hours surfing the internet. The research employed analysis of variance, frequency, and percentage tests applied to ascertain 
the degree of the relationship between the variables.

\section{Research Findings and Discussion}

To examine the relationship between SMPs and its impacts on employees' productivity and performance, 150 respondents that are working in different institutions have selected. So, the following section of this research addresses the analysis of data samples by using Statistical Package for Social Sciences (SPSS) software packages. In this segment, the conclusions of the experiential element of the investigation are asserted, explained and discussed. The respondents have requested to answer the four-page questionnaire with three sections. The results have exhibited in the subsequent section.

Features of the demographic and socio-economic determinants of the representation have addressed in Table 2, which displays that the participants include extensive arrays of age, marital status, qualification, etc. Respondents have questioned about their citizenship. This research has explained to them as the country of which they carry the passport document. It is worth remarkable that the influence of participants is from the Non-Saudi level with 70 percent. This statistics implies that the education institutions are further convinced to engage highly equipped imported individuals. Out of 150 respondents, 90 percent are male, and only 10 percent are female. The truth that the male respondents outweighed the female respondents compares with the total gender distribution. Most of the interviewees (88.7 percent) were married and belonged to the age section of 31-40 years with 57.3 percent. As far as occupancy is involved, 53.3 percent of the respondents are faculty staff. Furthermore, the high level of technological knowledge and practices among individuals has ascribed to the comparatively higher percentage rate of qualification achieved. The statistics pointed that 96.7 percent of the participants have secondary school certificate or more advanced.

Table 2. Demographic information of the respondents

\begin{tabular}{llcc}
\hline Information & Category & Frequency & Percentage (\%) \\
\hline Gender & Male & 135 & 90.0 \\
Marital Status & Female & 15 & 10.0 \\
& Single & 12 & 8.0 \\
Age & Married & 133 & 88.7 \\
& Divorced & 5 & 3.3 \\
& Below 20 years & 1 & 0.7 \\
& $21-30$ & 9 & 6.0 \\
& $31-40$ & 86 & 57.3 \\
Job Position & $41-50$ & 42 & 28.0 \\
Types of Institution & $51-60$ & 11 & 7.3 \\
& 61 above & 1 & 0.7 \\
Qualification Attained & Faculty staff & 80 & 53.3 \\
& Non-faculty staff & 70 & 46.7 \\
& Public & 96 & 64.0 \\
& Private & 54 & 36.0 \\
Nationality & Certificate & 1 & 0.7 \\
& Diploma & 4 & 2.7 \\
& Bachelor Degree & 15 & 10.0 \\
& Master Degree & 21 & 14.0 \\
& Doctorate & 109 & 72.7 \\
& Saudi citizen & 45 & 30.0 \\
& Non-Saudi & 105 & 70.0 \\
\hline
\end{tabular}




\section{MlMacrothink}

International Journal of Human Resource Studies

ISSN 2162-3058

2017, Vol. 7, No. 3

To ascertain the core of each respondent's status, the following section of the questionnaire questioned regarding each nature of the job post. Emphasis has installed on two broad categories of appointment, mainly temporary and permanent staff members. Table 3 demonstrates the employee appointment levels of which the majority was temporary staff with 84.7 percent.

Table 3. Nature of appointment

\begin{tabular}{lcc}
\hline Item & Frequency & Percentage (\%) \\
\hline Temporary Staff & 127 & 84.7 \\
Permanent Staff & 23 & 15.3 \\
\hline
\end{tabular}

The following review section has committed to building whether the respondents used social networking platforms, consumed time they spent if they involve in SMP and their views and preferences about this technology continued. This enigma was inserted in the questionnaire to authenticate the respondent's awareness with SMPs. The five platforms specified in the list presented are Facebook, Twitter, Tumblr, MySpace and LinkedIn.

As described in Table 4, the representation recognized one of the five successful SMPs named. Facebook confirmed to be a unique platform with 59.3 percent and 24.7 percent had registered profiles in LinkedIn which solely applied for business and professional connections. Tumblr was the least preferred platform within this sample with 1.3 percent. Nevertheless, respondents had the alternative to signify whether they pin up other SMPs like blogs or boards not posted but none of the interviewees showed either. These statistics reveals that all respondents share and participate in social media in the workplace one form or the other.

Table 4. Commonly used social networking sites

\begin{tabular}{lcc}
\hline Item & Frequency & Percentage (\%) \\
\hline Facebook & 89 & 59.3 \\
Twitter & 19 & 12.7 \\
Tumblr & 2 & 1.3 \\
MySpace & 3 & 2.0 \\
LinkedIn & 37 & 24.7 \\
\hline
\end{tabular}

The effect of time on SMPs has been one of the most contentious items as numerous researchers and scholars have opposed different outlooks on the topic. One of the primary intentions of the research was to carry out the measure of time spent by respondents on SMPs as these could determine the result of the time they had for their exercises. On average, 40 percent of respondents consumed more than 30 minutes to 1 hour per session when using SMPs in a day at work. Out of 150, 45 (30 percent) of respondents responded fewer. It can understand the evidence that the representation of respondents who engaged on SMPs during office hours may have a challenge evaluating their online actions and their education formation. This notion will, in turn, influence their studies accomplishment. 


\section{MInstitute Macrothink $^{m}$}

Table 5. Time spent surfing SMPs on a day at work

\begin{tabular}{lcc}
\hline Time spent (min-hrs) & Frequency & Percentage (\%) \\
\hline$<30$ mins & 30 & 20.0 \\
$>30$ mins-1 hour & 60 & 40.0 \\
$1-2$ hours & 45 & 30.0 \\
$2-4$ hours & 10 & 6.7 \\
$>4$ hours & 5 & 3.3 \\
\hline
\end{tabular}

The intention of this analysis was to explore what impact SMPs may have on employee productivity. A particular indicator of whether SMPs has implemented for work-related objectives was to ascertain the ideas why respondents adopted the technology, as illustrated in Table 6. Respondents showed that reading and writing in a forum was the enormously principal motive for attending SMPs with 48.7 percent. Playing games ( 8 percent), chatting with individuals ( 7.3 percent), and viewing /uploading images (9.3 percent) were the least named choice.

From these results, it seemed that SMPs has not utilized in a work-related practice. The assumption had made that the maximum amount that has summed to the respondents' daily lives about SMPs occurred on a social level. It could be that several respondents had not yet apprehended the implied importance that SMPs technology might supplement on a professional level. Nevertheless, several respondents did attest its value towards developing connections with 14.7 percent and participation in friends' profiles or group pages with 12 percent.

Table 6. Utilization of social networking sites

\begin{tabular}{lcc}
\hline Item & Frequency & Percentage (\%) \\
\hline Reading/ writing forum postings & 73 & 48.7 \\
Playing games & 12 & 8.0 \\
Making connections & 22 & 14.7 \\
Chatting, checking and replying messages & 11 & 7.3 \\
Viewing/uploading images, videos and commenting & 14 & 9.3 \\
Browsing friends profiles or group/fan pages & 18 & 12.0 \\
\hline
\end{tabular}

Regarding the frequency of visits to SMPs, respondents showed that Facebook was the further frequently platform visited. It was visited daily by 46.7 percent of the respondents, whereas other platforms were visited once in few weeks (10 percent). Respondents' decisions may have affected by the diverse environment of the posted SMPs, for instance, the social focus of Facebook compared the business focus of LinkedIn. This notion may explain that SMP technology has practiced further for social goals than to carry or advance respondents' business or daily work functions. The findings also preferred that a substantial section of the representation was enthusiastic to visit SMPs on either a daily or weekly basis, which meant an opportunity for virtual intercommunication within the organization. If employees continued the advantage of SMPs for personal views, they would seemingly also consider a related network proposed at their educational institution in respect. 


\section{Mll Macrothink}

International Journal of Human Resource Studies

ISSN 2162-3058

2017, Vol. 7, No. 3

Table 7. Frequency of visiting SNS at work

\begin{tabular}{lcc}
\hline Day spent & Frequency & Percentage $(\boldsymbol{\%})$ \\
\hline Once in few weeks & 15 & 10.0 \\
1-2 days/week & 29 & 19.3 \\
3-4 days/week & 36 & 24.0 \\
Daily & 70 & 46.7 \\
\hline
\end{tabular}

The research also managed a cross tabulation analysis between institution and number of online friends. The resolution of the inquiry exposed that majority of respondents 52 (34.7 percent) had between 101 and 200 friends in their SMPs profiles. 301-400 (11.3 percent) and 401 and above are the least perceived figure of friends within this representation with 6 percent, respectively. The higher symmetry of respondents with a few friends explained that this account is mostly produced to sustain existing relationships to their endeared friends rather than to create separate connections.

Table 8. Friends in SNS profiles

\begin{tabular}{lcc}
\hline No. of friends & Frequency & Percentage $(\boldsymbol{\%})$ \\
\hline Less than 100 & 38 & 25.3 \\
$101-200$ & 52 & 34.7 \\
$201-300$ & 26 & 17.3 \\
$301-400$ & 17 & 11.3 \\
$401-500$ & 9 & 6.0 \\
Greater than 500 & 8 & 5.3 \\
\hline
\end{tabular}

The investigation strived to examine for what purpose the respondents use SMPs most of the time in their workplace. As Table 9 indicates; four goals came out most strongly as the reasons for social media involvement in the workplace, which shows that participation can attribute to both work and non-work related purposes. The majority of respondents (46.7 percent) agreed that they engage in social media to search job-related information. 14.7 percent respondents use social media for locating their old or staying in touch with their current friends. 12 percent of the respondents agreed that they participate in social media to share information with colleagues and other friends. 26.7 percent of respondents agreed that they are involved in social media in the workplace to build their own business.

Table 9. Purpose of SNS

\begin{tabular}{lcc}
\hline Purpose & Frequency & Percentage (\%) \\
\hline Social & 22 & 14.7 \\
Business & 40 & 26.7 \\
Work purpose & 70 & 46.7 \\
Educational purpose & 18 & 12.0 \\
\hline
\end{tabular}

The last section of the questionnaire intended to discover the attitude and perceptions of the sample group concerning social media in their professional context. A question consisting eight statements has offered to respondents who had to rate each description according to a 
Likert scale that evaluated the standard to which respondents agreed or disagreed with each statement. These statements have descended from the literature review and exhibited in Table 10 here.

Table 10. Attitude and perception towards social media platforms

\begin{tabular}{ccccccccc}
\hline \multirow{2}{*}{ Scale } & \multicolumn{8}{c}{ Statements (\%) } \\
\cline { 2 - 9 } & C1 & C2 & C3 & C4 & C5 & C6 & C7 & C8 \\
\hline SD & 4.7 & 11.3 & 2.7 & 0.7 & 12.7 & 5.3 & 8.0 & 5.3 \\
D & 6.7 & 30.0 & 5.3 & 3.3 & 23.3 & 6.0 & 9.3 & 4.7 \\
PA & 9.3 & 23.3 & 8.0 & 23.3 & 37.3 & 23.3 & 16.7 & 12.0 \\
A & 26.0 & 20.0 & 18.0 & 34.0 & 10.0 & 28.0 & 13.3 & 20.7 \\
SA & 53.3 & 15.3 & 66.0 & 38.7 & 16.7 & 37.3 & 52.7 & 57.3 \\
\hline
\end{tabular}

Going by findings demonstrated in Table 10, respondents were advised to provide their viewpoint on the likelihood of SMPs thinking the increase in productivity at work in general. The effects explained that 53.3 percent of respondents strongly agreed and 26 percent agreed. This positive attitude has reverberated in the findings of the literature review that social media timeouts started as mental appetite disinfectants, it revives the mind to be able to undertake on unfinished assignments with a greater level of attentiveness. In fact, enough access to SMPs can progress employee productivity (Bennett et al., 2010). The decision to statement $\mathrm{C} 1$ meant that respondents understood the significance of SMPs regarding minute break. Coupled with the outcomes described in Table 6, it has surmised that the majority of the interviewees would employ SMPs for this purpose in the organizational context. Nevertheless, 30 percent of respondents disagrees that employee uses SMPs at work during proper break time, which exhibits in statement $\mathrm{C} 2$.

A SMP has become a portion of the Saudi culture, and it supports high-speed communication in the workplace. In statement C3, the respondents had granted a chance to reveal whether they think that SMPs are capable of augmenting the levels of employee performance and satisfaction when exercised carefully and effortlessly. The results found 66 percent strongly agreed and 18 percent agreed, which pinpoint that identifying the accomplishments and excellent performance of employee continues them inspired and satisfied. Moreover, it progresses skills and knowledge of the employee (Ashraf and Javed, 2014). They consider confined to the institution because they put in a position in which someone has admired for the achievement and the growth of their behavior within the standard. Furthermore, the majority of respondents strongly agreed (38.7 percent) and agreed (34 percent) that employees who are further social are real individuals in the work environment, which installed attention in statement $\mathrm{C} 4$.

The subsequent viewpoint of the respondent's attitudes and perception have traversed in statement C5 that employee can accurately control or limit the use of SMPs at work setting. A notable number of respondents are partially agreed with 37.3 percent while 23.3 percent disagrees. In the statement C6, examined the sample group's perception and attitude about the workplace basic approaches to building knowledge of effective SMPs utilization. Educational institutions must formulate a top caliber content that has arranged with their mission and 
concedes it frequently within their SMPs. In this investigation, the outcome marked those respondents, in fact, 37.3 percent often strongly agreed, and 28 percent of respondents were agreed. It likewise exhibited that if employees are well competent while addressing events on time, then it is irrelevant if there is an unrestricted use of SMPs during legitimate working hours. But, extreme use of SMPs can occur in a critical execution of responsibility advancing to employee productivity depredation (Warnakula \& Manickam, 2010).

Lastly, the questionnaire studied respondents' opinions regarding the influence of SMPs in the educational institutions. In statement C7, illustrated that majority of those surveyed (52.7 percent strongly agreed) and (13.3 percent agreed) considered that there is a possible peril from employees involving without reserve in an accessible social network. An illustration of logical uncertainties are scammers who may attempt to hijack personal information of individuals for an illegal crime such as identity theft or fraud and phishing attacks associated with SMPs (Eke et al., 2014). When the threats of unlimited access to SMPs happen, actions have to be acknowledged and applied by an ICT department to shield the institution's information systems. According to Kavanagh (2012) holding the organizational devices security is necessary, and effecting limitations is a small amount to spend to impede such circumstances. Consequently, in statement $\mathrm{C} 8$, the results explained that several respondents strongly agreed (57.3 percent) or agreed (20.7 percent) that institutions stand in need for suitable policies and regulations to observe the uses of SMPs with its employees.

\section{Conclusion and Recommendations}

The modern marketplace influenced by innovation technology, gassed by information, and inspired by knowledge has unfolded different opportunities on the slope. In this research, it proves that if not well controlled, social media involvement may direct to a decline of productivity. Kidwell (2010) unveiled that the workplace of the twenty-first century would have the possibility to contribute innovative approaches and avenue for difficulty employees to elongate the dense culture of keeping discipline from the line of work. An experienced and self-driven workforce is presumably one of the national resources of the Kingdom. But barely sufficient human resources are inspired to build societies and virtual private network within social media to provide to knowledge creation and sharing of information. This perception was manifest from the literature review which described that social media gave a different mechanism for knowledge creation and collaborated on current initiatives that will deliver tangible advantage to business strategies. Within the decisive and well-defined use of social media, educational institutions can produce a healthy productive community to improve the structure of knowledge production, exchange, and directions within distinguished education (Lang and Lemon, 2014).

To escalate the potential of SMPs within the institutions, the researchers recommended that organizations should consider in developing and implementing clear and complete acceptable use policies when strive to arrange with SMPs issues. Such matters are individual usage, online site limitations, data and information confidentiality, and business importance without checking employees to benefit personally as well as professionally from this social web technology. Furthermore, this will guarantee that employees are cognizant of what remains 
authorized about SMPs, what possibilities required from a professional and personal viewpoint and what the technical indications occur. Apparently, management policies on users using social media should have shielded so that employees will not overlook their initial intention of staying in the educational institutions.

\section{References}

Ashraf, N. \& Javed, T. (2014). Impact of social networking on employee performance. Business Management and Strategy, 5(2), 139-150. https://doi.org/10.5296/bms.v5i2.5978

Baghdadi, A. (September 23, 2015). How Social Media Is Dominating the Saudi Market. http://news.arabnet.me/social-media-dominating-saudi-market-insights-facebook-instagram-t witter-youtube/

Bennett, J., Owers, M., Pitt, M., \& Tucker, M. (2010). Workplace impact of social networking. Property Management, 28(3), 138 - 148. https://doi.org/10.1108/02637471011051282

Bonds-Raacke, J. \& Raacke, J. (2010). MySpace and Facebook: Identifying dimensions of uses and gratifications for friend networking sites. Individual Differences Research, 8(1), 27-33.

Bosker, B. (March 10, 2012). Vic Gundotra, Google's Social Chief, Explains What Google+ Is (But Not Why To Use It). Huffington Post.

Cox, J. T., \& Rethman, K. M. (2011). Setting expectations: Social networking at work. Ohio Lawyer, 17-19.

Eke, H. N., Omekwu, C. O., \& Odoh, J. N. (2014). The Use of Social Networking Sites among the Undergraduate Students of University of Nigeria, Nsukka. Library Philosophy and Practice (e-journal). Paper 1195. Available at http://digitalcommons.unl.edu/libphilprac/1195

Griesemer, J. A. (2014). Using social media to enhance students' learning experiences. Quality Approaches in Higher Education, 3(1), 8-11. Available at: www.asq.org/edu/index.html.

Hantula, D. A., Kock, N., D’Arcy, J. P., \& DeRosa, D. M. (2011). Media compensation theory: A Darwinian perspective on adaptation to electronic communication and collaboration. Evolutionary Psychology in the Business Sciences. Berlin, Germany: Springer-Verlag.

Kavanagh, R. (2012). Does social media hamper productivity? Chartered Management Institute. Available at http://www.managers.org.uk/insights/news/2012/february/does-social-media-hamper-workpla ce-productivity

Kidwell, R. E. (2010). Loafing in the 21st century: Enhanced opportunities and remedies for withholding job effort in the new workplace. Business Horizons, 53(6), 543-552. https://doi.org/10.1016/j.bushor.2010.06.001

Lang, C. \& Lemon, N. (2014). Embracing Social Media to Advance Knowledge Creation and Transfer in the Modernized University: Management of the Space, the Tool, and the Message. 


\section{Macrothink}

International Journal of Human Resource Studies

ISSN 2162-3058

2017, Vol. 7, No. 3

In Advancing knowledge in higher education: Universities in turbulent times (1st ed., pp. 112-131). Hershey, PA: IGI Global. https://doi.org/10.4018/978-1-4666-6202-5.ch008

Larson, E. (2013). How many teachers use technology in the classroom? Available at http://mashable.com/2013/02/05/teachers-technology-infographic/\#a93z46ssGZqC

Leonardi, P. M., Huysman, M. \& Steinfield, C. (2013). Enterprise Social Media: Definition, History, and Prospects for the Study of Social Technologies in Organizations. Journal of Computer-Mediated Communication, 19, 1-19. https://doi.org/10.1111/jcc4.12029

Linna, P., Pekkola, S., Ukko, J. \& Melkas, H. (2010). Defining and measuring productivity in the public sector: Managerial perceptions. International Journal of Public Sector Management, 23(3), 300-320. https://doi.org/10.1108/09513551011032491

Papandrea, M-R. (2012). Social Media, Public School Teachers, and the First Amendment. North Carolina Law Review, 90, 1597-1642. Available at: http://lawdigitalcommons.bc.edu/lsfp

Sait, S. M., Al-Tawil, K. M., Sanaullah, S. \& Faheemuddin, M. (2007). The impact of Internet Usage in Saudi Arabia: A Social Perspective. International Journal of Information Technology and Web Engineering, 2(2), 81-115. https://doi.org/10.4018/jitwe.2007040104

Seaman, J. \& Tinti-Kane, H. (2013). Social Media for Teaching and Learning. Massachusetts, USA: Pearson Learning Solutions and Babson Survey Research Group.

Warnakula, W. M., \& Manickam, B. (2010). Employees' behaviour in online social networking websites (SNSs). Tropical Agricultural Research, 22(1), 94-106.

\section{Copyright Disclaimer}

Copyright for this article is retained by the author(s), with first publication rights granted to the journal.

This is an open-access article distributed under the terms and conditions of the Creative Commons Attribution license (http://creativecommons.org/licenses/by/4.0/). 